\title{
SKELETAL MATURATION EVALUATION USING MANDIBULAR SECOND MOLAR CALCIFICATION STAGES
}

\author{
Fakhira Nizam, Nasrullah Mengal, Mirza Tareen, Sumbal Hayat \\ Sandeman Provincial Hospital, Quetta Pakistan
}

\begin{abstract}
Objective: To examine the relationship between skeletal maturity and mandibular second molar calcification stages and assessing mandibular second molar as a diagnostic tool for skeletal maturity evaluation.

Study Design: Cross sectional study.

Place and Duration of Study: Orthodontic department, Sandeman Provincial Hospital, Quetta, from Jan to Jun 2019.

Methodology: The sample size of the study 240 comprised of equal number of males and females. Inclusion criteria was defined to include the patients (male and female) with the age from 9-16 years; on the same time, patients without facial asymmetry and without prior history of facial or neck trauma/injury or surgery were considered for the present study. Exclusion criteria was defined to exclude those patients from the study hoe had the history of bone disease and major illness in past; known cases of muscular dystrophy; any congenital malformation of cervical vertebrae and tooth caries; Low quality x-ray with poor contrast.

Results: The study revealed association between Demirjian Index and Cervical Vertebrae Maturation Index stages (0.875) with the statistical significance. Demirjian Index Stage H indicated the greater percentage distribution at stage 4 and 6 of Cervical Vertebrae Maturation for males. Similarly, in females, demirjian index stages $\mathrm{G}$ and $\mathrm{H}$ showed the greater percentage at stage 4 and 6 of cervical vertebrae maturation index respectively.

Conclusion: Analysis indicated that cervical vertebrae maturation index and Demirjian Index (DI) occurred earlier in females than males.
\end{abstract}

Keywords: Cervical vertebra maturation, Mandibular second molar calcification, Skeletal maturation.

This is an Open Access article distributed under the terms of the Creative Commons Attribution License (https://creativecommons.org/licenses/by-nc/4.0/), which permits unrestricted use, distribution, and reproduction in any medium, provided the original work is properly cited.

\section{INTRODUCTION}

Assessment of dental development and skeletal maturity is a clinical practice which is common in most of health professions particularly for growth modification in orthodontic. In growing patients ${ }^{1}$, orthodontic treatment with jaw discrepancies involved growth modification with the use of orthopedic functional appliances $^{2}$. In 1975, Lamparsky indicated that morphologic changes in cervical vertebrae can also be used alternatively for the evaluation of skeletal maturity 4 . Specific stages of physiologic maturity is base of the maturity state of a child then chronological age ${ }^{5}$.

For assessing the skeletal maturity inclusive of chronological age, dental development ${ }^{1}$, there are different methods which has been supported by various authors determining skeletal maturity on the basis of radiographs of specific structures, such as epiphysis diaphysis fusion of long bone, and fusion of the sphenoid bone with basilar part of the occipital bone ${ }^{6}$. For the evaluation of adolescent development, the epidemic age of the examined tooth and the mineralization of second molar calcification stages on panoramic

Correspondence: Dr Fakhira Nizam, Orthodontics Department, Sandeman Provincial Hospital, Quetta Pakistan

Received: 19 Dec 2019; revised received: 25 Jun 2020; accepted: 09 Jul 2020 radio graph has been described in demirjian method ${ }^{7}$ by which dental maturity can be determined. For the evaluation of dental maturity of young children $(<6.5)$, demirjian method is found to be an accurate method. In case of less old children ${ }^{8}$ dental maturity assessment is a simple procedure to execute on panoramic radio graphs used for various purposes ${ }^{9}$.

There is a highest correlation indicated between mandibular second molar calcification stage and skeletal maturity in comparison of other teeth ${ }^{10}$ Demirjian et al index described that there are 6 maturation stages of cervical vertebrae as suggested by Rajagopal et al; whereas there are eight stages (A to $\mathrm{H}$ ) of mandibular second molar tooth calcification as defined by demirjian index ${ }^{10}$.

It was an objective of the study to assess skeletal maturational age with the use of mandibular left second molar to carry out on panoramic radio graphs and comparing it with cervical vertebra maturation index (CVMI) by hassal and farman on lateral Cephalometric considering as standard. There are several studies on skeletal maturity indicators, however researchers paid a little attention to the relations between cervical vertebra maturation index (CVMI) and mandibular left second molar calcification stages. A research was 
conducted on 300 patients with age ranging from 9-18 years. In that research, CVMI and mandibular second molar calcification stages were compared. Results indicated the strong association between CVMI and DI ( $\mathrm{r}=$ 0.854 for males and $\mathrm{r}=0.866$ for females) ${ }^{1}$.

\section{METHODOLOGY}

This descriptive cross sectional study was conducted in Sandeman Provisional Hospital Quetta, from January to June 2019. Sample size was set to 240 . Nonprobability consecutive technique was used as sampling technique for the collection of data.

Inclusion criteria was defined to include the patients (male and female) with the age from 9-16 years; on the same time, patients without facial asymmetry and without prior history of facial or neck trauma/injury or surgery were considered for the present study. Furthermore, those patients, whose bones appeared clearly on the radio graph and first four cervical vertebrae inferior border were clear.

Exclusion criteria was defined to exclude those patients from the study hoe had the history of bone disease and major illness in past; known cases of muscular dystrophy; any congenital malformation of cervical vertebrae and tooth caries; low quality $\mathrm{x}$-ray with poor contrast.

Previous history of bone disease and major illness in past; known cases of muscular dystrophy; any congenital malformation of cervical vertebrae and tooth caries; Low quality x-ray with poor contrast. The study was conducted after the permission of Hospital's ethics committee and patients' informed written consent.

Visual inspection by Hassal and Farman et al was used for evaluating CVMI. This method determined anatomical changes of $\mathrm{C} 2, \mathrm{C} 3$, and C4, evaluated concerning two sets of variables: (1) the presence or absence of a concavity in C2 (odontoid process), C3, and C4 at the inferior border and (2) Shape differences of the body of cervical vertebrae with the progressive ages, with the consideration of four shapes. The variables were subdivided into six consecutive stages in cervical maturation (CVMI-1-CVMI-6). Six cervical vertebral maturation (CVMI) index according to Rajagopal et al.

This study used Demirjian Index (DI) method 1 is for evaluating left mandibular second molar on panoramic radiographs from stage $\mathrm{A}$ to stage $\mathrm{H}$.

The data entry and analysis was done using program SPSS ver 20. Frequencies and percentages of the categorical variables i.e. CVMI and DI stages were presented andcomparedby using ANOVA. The age distribution of patients was plotted in MS Excel as shown in figure.

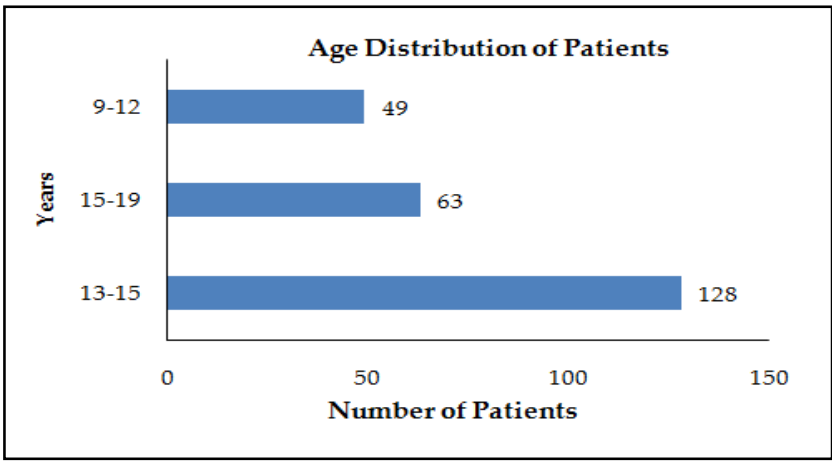

Figure-1: Age distribution.

\section{RESULTS}

Total number of respondents was 240; and the gender distribution shows that $120(50 \%)$ were males and $120(50 \%)$ were females. Mean age was calculated to be $13.87 \pm 2.099$ years.

The frequency distribution of various stages of CMVI across each of the gender as shown in the tableII along with the mean age of patients. From total 240 patients, $35(14.5 \%)$ males and $36(15 \%)$ females were reported for CMVI 6 with the mean age of 16.66 and 15.48 years respectively as shown in the table-I.

Table-I: Gender and mean age of the respondents.

\begin{tabular}{l|c}
\hline Gender & Age (Mean \pm SD) \\
\hline Male & $14.22 \pm 2.03$ \\
\hline Female & $13.11 \pm 2.01$ \\
\hline
\end{tabular}

Table-II: Frequency distribution and mean age of males and females.

\begin{tabular}{l|c|c|c}
\hline $\begin{array}{l}\text { Cervical Vertebrae } \\
\text { Maturation Index }\end{array}$ & Gender & $\mathbf{n ~ ( \% )}$ & Mean \pm SD \\
\hline \multirow{2}{*}{ Stage 1} & Male & $6(3)$ & $10.11 \pm 0.18$ \\
\cline { 2 - 4 } & Female & $10(4)$ & $9.39 \pm 0.31$ \\
\hline \multirow{2}{*}{ Stage 2 } & Male & $11(5)$ & $11.51 \pm 0.56$ \\
\cline { 2 - 4 } & Female & $12(5)$ & $10.66 \pm 0.32$ \\
\hline \multirow{2}{*}{ Stage 3 } & Male & $15(6)$ & $12.55 \pm 0.15$ \\
\cline { 2 - 4 } & Female & $16(7)$ & $11.65 \pm 0.28$ \\
\hline \multirow{2}{*}{ Stage 4 } & Male & $26(11)$ & $13.56 \pm 0.36$ \\
\cline { 2 - 4 } & Female & $28(12)$ & $12.83 \pm 0.29$ \\
\hline \multirow{2}{*}{ Stage 5 } & Male & $27(11)$ & $14.66 \pm 0.38$ \\
\cline { 2 - 4 } Stage 6 & Female & $18(8)$ & $13.82 \pm 0.19$ \\
\hline
\end{tabular}

\section{DISCUSSION}

In the clinical practice, the assessment of growth of patients`status is very important. Skeletal maturity assessment and dental development is very common 
Table-III: Cervical vertebrae maturation index (CVMI) and demirjian index (DI) in females.

\begin{tabular}{|c|c|c|c|c|c|c|}
\hline Cervical Vertebrae Maturation Index & $E(n(\%))$ & $F(n(\%))$ & & $\mathrm{G}(\mathrm{n}(\%))$ & $\mathbf{H}(\mathrm{n}(\%))$ & $p$-value \\
\hline 1 & - & - & & - & - & \multirow{7}{*}{$<0.01$} \\
\hline 2 & $12(11)$ & - & & - & - & \\
\hline 3 & $3(3)$ & $11(10)$ & & $2(2)$ & - & \\
\hline 4 & - & \multirow{2}{*}{$\begin{array}{l}8(7) \\
3(3)\end{array}$} & & $20(18)$ & - & \\
\hline 5 & - & & & $15(14)$ & - & \\
\hline 6 & - & - & & $5(5)$ & $31(28)$ & \\
\hline Total & $15(14)$ & $22(20)$ & & $42(38)$ & $31(28)$ & \\
\hline \multicolumn{7}{|c|}{ Table-IV: Cervical vertebrae maturation index (CVMI) and demirjian index (DI) in males. } \\
\hline Cervical Vertebrae Maturation Index & D & E & $\mathbf{F}$ & G & $\mathbf{H}$ & $p$-value \\
\hline 1 & $6(5)$ & - & - & - & - & \multirow{7}{*}{$<0.01$} \\
\hline 2 & - & $2(2)$ & $9(8)$ & - & - & \\
\hline 3 & - & $3(3)$ & $8(7)$ & $4(3)$ & - & \\
\hline 4 & - & - & $10(8)$ & $16(13)$ & - & \\
\hline 5 & - & - & - & $4(3)$ & 23 (19) & \\
\hline 6 & - & - & - & $7(6)$ & $28(23)$ & \\
\hline Total & $6(5)$ & $5(5)$ & $27(25)$ & $31(28)$ & $51(46)$ & \\
\hline
\end{tabular}

clinical practice in the number of health professions, particularly for growth reform inorthodontics and dentofacial orthopedics and for the age estimation in forensic sciences ${ }^{11-14}$. This cross-sectional study was conducted in an effort to clarify the relationship between mandibular second molar calcification stage and skeletal maturation among a group of Pakistani orthodontic patients.

Previous studies reported racial variations between individual teeth calcification stages and skeletal maturity ${ }^{14}$. Consequently, this study was planned examined the relationship between the stages of calcification of mandibular second molar teeth and skeletal maturity stages in this population.

The developmental status of an individual is usually assessed in connection to physical events taking place during the progress of growth. Therefore Indicators of developmental age are more informative than chronological age, specifically for age estimation and clinical application ${ }^{15}$.

DI stage $\mathrm{H}$ indicated the greater percentage distribution at stage 4 and 6 of CVM for males. Similarly, in females, DI stage $\mathrm{G}$ and $\mathrm{H}$ showed the greater percentage at stage 4 and 6 of CVMI respectively. Our findings presented different results in comparison to the findings of Kumar et al ${ }^{16}$. Their research reported the peak skeletal growth spurt at slightly different stages of dental maturity. The significant findings from the study of Vijayashree et al indicated that mandibular second molar calcification stages are considered as the reliable indicator of skeletal maturity, which can be used for the prediction of growth status in the way to determine the optimal timing of treatment ${ }^{17}$.

\section{CONCLUSION}

Frequency distribution of DI stages indicated greater percentage at stage 4 and 6 of CVMI in males. Similarly, DI stage $\mathrm{G}$ and $\mathrm{H}$ showed the greater percentage stage 4 and 6 of CVMI in females respectively. Analysis indicated that cervical vertebrae maturation index and demirjian index (DI) occurred earlier in females than males.

\section{CONFLICT OF INTEREST}

This study has no conflict of interest to be declared by any author.

\section{REFERENCES}

1. Kumar S, Singla A, Sharma R, Virdi MS, Anupam A, Mittal B. Skeletal maturation evaluation using mandibular second molar calcification stages. Angle Orthod 2012; 82(3): 501-06.

2. Danaei SM, Karamifar A, Sardarian A, Shahidi S, Karamifar H, Alipour A, et al. Measuring agreement between cervical vertebrae and hand-wrist maturation in determining skeletal age: Reassessing the theory in patients with short stature. Am J Orthod Dentofacial Orthop 2014; 146(3): 294-98.

3. Mellion ZJ, Behrents RG. The pattern of facial skeletal growth and its relationship to various common indexes of maturation. Am J Orthod Dentofacial Orthop 2013; 143(6): 845-54.

4. Beit $P$, Peltomäki T, Schätzle M, Signorelli L, Patcas R. Evaluating the agreement of skeletal age assessment based on hand-wrist and cervical vertebrae radiography. Am J Orthod Dentofacial Orthop 2013; 144(6): 838-47.

5. Prasad M, Ganji VS, George SA, Talapaneni AK, Shetty SK. A comparison between cervical vertebrae and modified MP3 stages for the assessment of skeletal maturity. J Nat Sc Biol Med 2013; 4(1): 74 .

6. Mehta N, Patel D, Mehta F, Gupta B, Zaveri G, Shah U. Evaluation of skeletal maturation using mandibular third molar development in Indian adolescents. J Forensic Dent Sci 2016; 8(2): 112.

7. Arvindbhai SB, Yusuf AR. Radiographic evaluation of skeletal maturity using maxillary canine and mandibular second molar calcification stages in western maharashtra population. A retrospective study. Int J Cont Med Sci 2016; 3(6): 1750-54. 
8. Baghdadi ZD. Dental maturity in Saudi children using the demirjian method: a comparative study and new prediction models. Intl Schol Res Netw 2013; 2013: 1-5.

9. Surendran S, Thomas E. Tooth mineralization stages as a diagnostic tool for assessment of skeletal maturity. Am J Orthod Dentofac Orthop 2014; 145(1): 7-14.

10. Kumar S, Singla A, Sharma R, Virdi MS, Anupam A, Mittal B. Skeletal maturation evaluation using mandibular second molar calcification stages. Angle Orthod 2012; 82(3): 501-06.

11. Perinetti G, Contardo L, Gabrieli P, Baccetti T, Di Lenarda R. Diagnostic performance of dental maturity for identification of skeletal maturation phase. Eur J Orthodont 2012; 34(4): 487-92.

12. Rajagopal R, Kansal S. A comparison of modified MP3 stages and the cervical vertebrae as growth indicators. J Clini Orthodont 2002; 36(7): 398-406.

13. Franchi L, Baccetti T, De Toffol L, Polimeni A, Cozza P. Phases of the dentition for the assessment of skeletal maturity: a diagnostic performance study. Am J Orthod Dentofac Orthop 2008; 133(3): 395-400.

14. Mcnamara JR, Franchi L, bacceji T. The cervical vertebral maturation method for the assessment of optimal treatment timing in dentofacial orthopaedics. Semin Orthod 2005; 11(3): 119-29.

15. Demirjian A, Buschang PH, Tanguay R, Patterson DK. Interrelationships among measures of somatic, skeletal, dental, and sexual maturity. Am J Orthodont 1985; 88(5): 433-38.

16. Kumar S, Singla A, Sharma R, Virdi MS, Anupam A, Mittal B. Skeletal maturation evaluation using mandibular second molar calcification stages. Angle Orthodont 2012; 82(3): 501-06.

17. Vijayashree U, Pai V, Naik V. Second molar calcification stages to evaluate skeletal maturation: A cross-sectional radiographic study. Trends Orthodont 2014; 4(6): 156.

18. Goyal S, Goyal S, Gugnani N. Assessment of skeletal maturation using mandibular second molar maturation stages. J Clin Pediatr Dent 2014; 39(1): 79-84. 